\title{
Solid/Liquid Dispersions in Drilling and Production
}

\author{
Y. Peysson ${ }^{1}$ \\ 1 Institut français du pétrole, 1 et 4, avenue de Bois-Préau, 92852 Rueil-Malmaison Cedex - France \\ e-mail: yannick.peysson@ifp.fr
}

Résumé - Fluides chargés en forage et production pétrolière - Pour atteindre les nouveaux gisements de pétrole, l'industrie pétrolière met en place des forages et des schémas de production de plus en plus complexes. Les puits de forage sont maintenant fortement déviés, horizontaux, multidrains, situés en offshore très profond, etc. Les forages déviés dépassent aujourd'hui les $10 \mathrm{~km}$ de déport et les puits forés en offshore explorent des sites où les profondeurs d'eau approchent les $3 \mathrm{~km}$ ! Les techniques de forage et de production utilisées exigent une maîtrise de plus en plus grande des paramètres mis en jeu et notamment la maîtrise des propriétés de nombreux fluides chargés. Ces fluides sont des dispersions plus ou moins concentrées de particules solides dans un fluide porteur. Ils se retrouvent fréquemment dans l'industrie pétrolière (fluides de forage, ciments, dispersion d'hydrates dans les effluents, venue de sables avec les fluides de réservoir, gravel pack, slurries de déblais, etc.).

Ces milieux divisés solide/liquide peuvent avoir des propriétés particulières parfois à la frontière entre le solide et le liquide : contrainte seuil, propriété rhéofluidifiante, etc. La description de leurs propriétés n'est pas aisée et nécessite d'aborder de nombreuses thématiques scientifiques : rhéologie, chimie et physicochimie, hydrodynamique, thermodynamique, etc.

Ce dossier thématique tentera d'effectuer une synthèse des différentes problématiques reliées aux fluides chargés, de présenter les propriétés communes de ces systèmes et d'aborder les nombreuses études engagées par l'IFP dans ce domaine.

\footnotetext{
Abstract - Solid/Liquid Dispersions in Drilling and Production — To reach the new oil and gas fields, the oil industry is developing more and more sophisticated drilling and production schemes. Wells trajectories are now deviated, horizontal, with high extended reach, multibranched, ultra deep offshore, etc. Extended reach wells are up to $10 \mathrm{~km}$ and offshore drilling is close to $3000 \mathrm{~m}$ of water depth! In these cases, drilling and production techniques are pushed to the limits. The operating conditions, the properties of the different materials employed must be controlled and operated in a more accurate way. This is the case for solid/liquid dispersions that are common in these operations: drilling fluids, cements, hydrates dispersions oil and gas phases, sand venue with reservoir fluids, etc.

These mixtures present some specific properties that can be at the limit between solid or liquid behaviour. For particular conditions the solid phase can create structures able to support large stresses and in others circumstances the mixture can flow like a viscous paste. Modeling of these characteristics is not easy and needs to use knowledge of different areas: rheology, physicochemistry, hydrodynamics, thermodynamics, etc.

In this revue, different systems used in the drilling and production industry will be discussed. Main properties of these systems and different development conducted by IFP will be addressed.
} 


\section{INTRODUCTION}

Since the first oil field discovered and drilled by Colonel Drake in 1859 in Pennsylvania around $880 \mathrm{Gbbl}$ have been produced! And each year, more than $25 \mathrm{Gbbl}$ of oil are produced, transported, transformed and used for electricity production, chemical synthesis, ground, air and sea transportation, etc.

In the first decades of its existence, from the middle of the 19th century to the early 20th century, the oil industry developed mainly in the United States and in Russia. Lightning with oil lamps was the first main market for this newborn industry. The demand for this new source of light increased quickly, pushed also by the use as a new source of energy and so rapidly the exploration extended to South America (Mexico and Venezuela) and to the Middle-East were huge fields were discovered.

During the 20th century, the development of modern industry and the raise of transportation by car, lead to a demand for a huge quantity of fossil energy. A large effort of investigation was made. Every continent was drilled and explored. After the Second World War, a large movement of nationalization of the production was launched in different countries to get rid of the dependency on western oil companies. This movement and the understanding of the strategic weight of this energy motivated western countries to look for a diversification of oil sources. Large investments for exploration were launched in the second part of the 20th century and new areas like the North Sea were discovered.

For years, oil fields on shore in different parts of the world were sufficient to face the demand. But in the second part of the 20th century, more and more complex zones were explored. Offshore and deep offshore drilling, extended reach wells, horizontal wells, multibranches wells were developed to explore and produce in more and more difficult environments.

Nowadays, complex drilling and production schemes are usual to produce fields in very difficult areas. The techniques used have evolved to face these new challenges. The need to control in a more accurate way the different techniques implies a considerable effort of research and development. In this dossier, we will focus specifically on fluids and solid dispersion for drilling and production. Indeed, if the goal of the oil industry is to produce liquid, several fluid and solid dispersions are present when oil wells are drilled or produced. A large range of characteristics can be achieved when mixing solids and liquids in terms of flow properties or in terms of material properties.

A first liquid/solid system that is central is the drilling fluid. The drilling technique named "rotary drilling" consists of the rotation from the surface of a pipe assembly ended with a cutting tool. The weight of the assembly is the driving force to dig the hole. Simultaneously, a fluid is pumped through the drill pipes to the cutting tool and rises in the annular space lifting up rock cuttings. At first, water was pumped and the mixing process with clays formed quickly a mud. The name stayed but the "drilling muds" are now complex fluids with many different chemical components designed to give specific properties. The hydrostatic pressure in the well is a critical point and it has to be carefully controlled compared to pore and fracture pressure of the drilled rock. A solid powder is mixed with the mud to adjust density leading to a dispersed media of complex structure. Drilling muds are also designed to transport rock cuttings from the bottom hole to the surface. Yield properties and drag forces on cuttings are then needed, giving very interesting complex rheological fluids.

When hundreds of meters are drilled, metal tubes are introduced in the well to ensure mechanical resistance of the hole. This "casing operation" requires cementing to seal the tubes in their lower part or sometimes over their entire length. Cement is injected through a specific pipe assembly and is placed in the annular space between borehole and casing in an operation called "primary cementing". The hole is still full of mud when this operation takes place, so drilling mud removal and cement placement are essential to ensure success of the primary cementing operation. The cement used is a solid/liquid suspension composed of small particles of several mineral phases in water at high volume fraction. Different chemical reactions like water dissolution and hydration turn the liquid cement into a solid plug that is able to seal the tubes in the well. Flow properties of such complex and reactive mixture are of high importance to control the cementing operation in complex well geometry.

A very different solid/liquid system can be found when producing in offshore and deep offshore environment: gas hydrate particles in oil and gas fluids. Gas hydrate crystals are water molecules forming cages with gas molecules trapped within. This structure is stable in well defined thermodynamics conditions. The complex assembly of such crystals creates a solid phase in the hydrocarbon fluids that can block the pipe. Hydrate issues are nowadays crucial for flow assurance in offshore developments. Contrary to cement or drilling mud, the solid phase is not added to the fluid on purpose to give specific characteristics. This solid phase occurs spontaneously and must be treated and controlled in different ways to avoid blockage of the flow line. This system has been largely investigated because of the increasing development of production in offshore and deep offshore environment.

We present here briefly the main dispersions used in drilling and production operations but some others are also involved in specific cases. Because of the large application of these different mixtures, many different aspects are studied at IFP and some of them will be presented in this thematic dossier. Details on the different systems will be given in the Section 1, and then some specific common properties will be 
discussed. We will end with an introduction to the detailed papers of this dossier concerning different fluid/solid media.

\section{THE SOLID/LIQUID SYSTEMS}

Three particular systems have motivated a substantial research effort to understand and characterize their behaviour: drilling fluid, cement and hydrate dispersions. Other solid/liquid system like sand slurries will also be presented in this Section.

\subsection{Drilling Fluids}

Drilling muds are now complex fluids made with many different components. Two main families can be found depending on the based fluid: water-based mud (WBM) and oil-based mud (OBM). Water based muds are mainly clays suspensions with polymers additives; oil based muds are emulsions of brine (around 30\% in volume) in an oil phase with surfactants, polymers and diverse chemicals additives.

Several properties are needed for these fluids. First, rock cuttings must be removed from the well to the surface. So, on the one hand, apparent viscosity must be high enough to assure sufficient drag on the solids, but on the other hand, it cannot exceed a certain value to limit the pressure drop due to the flow. The drilling muds must also avoid settling of the solid phase when circulation is stopped. So a "yield stress" is needed at rest. The amount and the nature of clays and polymers additives control these properties.

Viscosity is the first key issue for drilling muds, but density is the second. Indeed, in the drilling operation, the bottom hole pressure has to be controlled carefully. The pressure in the well must exceed the pore pressure of the geological formations and must not go above the fracture pressure of the different rocks drilled. Below this pressure range, fluid or gas venue can damage the drilling operation, and above it, mud losses or mechanical instability of the well could occur. A solid powder is thus used as a weighting agent. Mixing or dilution allows an accurate control of its value.

Because of this "overbalanced" pressure in normal drilling conditions, diffusion of the fluids in the porous media is possible. To decrease as much as possible this invasion, a filter cake is formed at the well wall. This film must be of weak permeability and must be easily removed when cementing operations or completion occur. The porous media around the well bore must return to its initial permeability. Specific compounds, like resins for example, are used as filtrate reducers.

Viscosity, density and filtration are controlled regularly in the field. Figure 1 shows the instruments to control viscosity. The Marsh funnel viscometer is a very simple vessel where the time that it takes to empty the vessel is a representation of the viscosity. For example, $26 \mathrm{~s}$ is the characteristic time for water. Nowadays the Fann 35 rheometer with coaxial cylinder is widely used permitting the determination of nonNewtonian parameters.

Aqueous solutions of polymer, clays, chemical additives, solid powder, etc., generate a very complex fluid from a physicochemical point of view. Physicochemical characteristics of the mud such as compatibility with the different rock formations drilled or stability of the components with time or with temperature, are essential. We will not go into more details on this aspect of mud properties (this could be a specific dossier in itself!), we will focus here on the physical properties on this dispersed system.
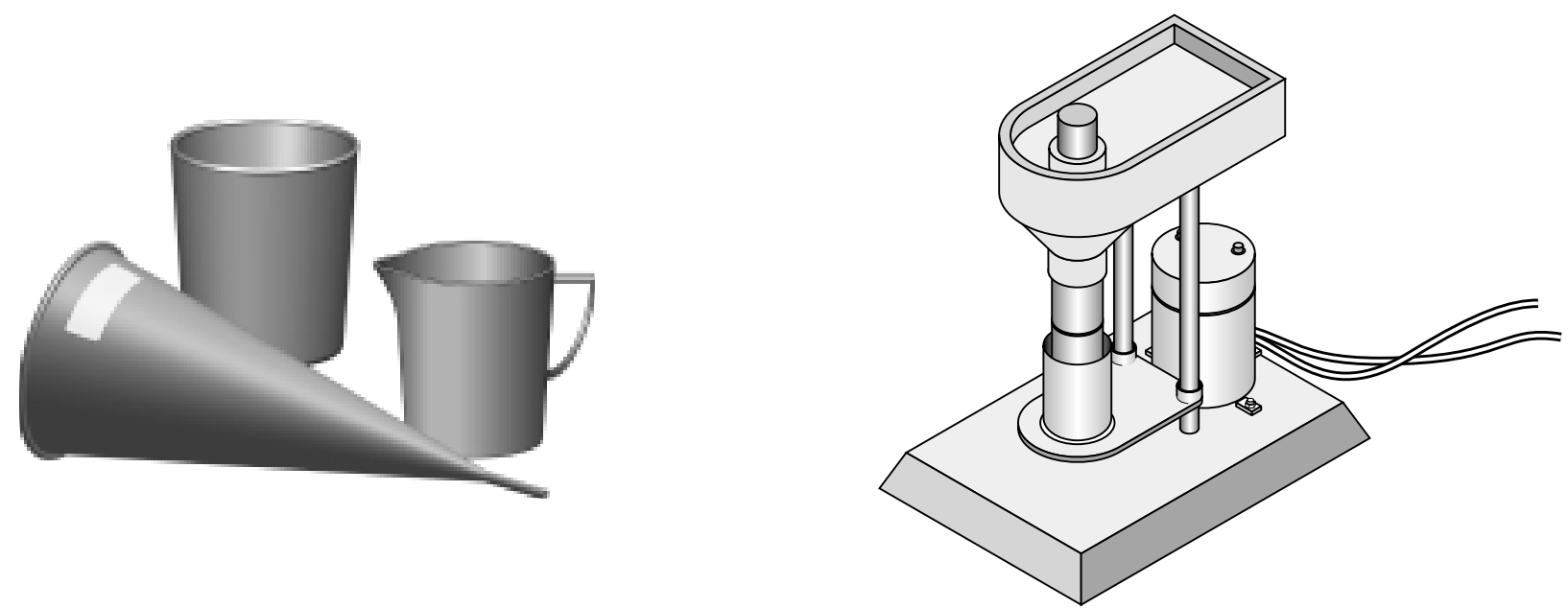

Figure 1

Marsh funnel viscometer and Fann 35 viscometer. 


\subsubsection{The Solids}

We can consider drilling mud itself as a dispersed medium. The large amount of weighting agent yields problems specific to dispersed systems such as, for example, sedimentation of the powder. This mechanism can occur in specific conditions and loss of the properties can damage the drilling operations. This phenomena called "barite sag" (barite is used as a weighting agent) is still not well understood.

In the mud, the interactions between the fluid and the solid phase create a complex dependency between shear stress and shear rate. Time evolution of the apparent viscosity, shearthinning and gelation is observed. The control of the apparent viscosity of the mud is important. Field measurements were for a long time very simple (mud viscosity was defined by only one parameter, the Marsh funnel viscosity). The Fann 35 field rheometer with six shear rate measurements allows a better characterization of the non- Newtonian behaviour. Pressure drop determination is then more accurate. However, some problems are still observed: low shear measurements are not accurate and yield stress determination is not satisfactory.

\subsubsection{Hole Cleaning}

Even if drilling muds can themselves be considered as dispersed media, the solids essentially come from the rock cuttings drilled. Hole cleaning determination is a very important issue in the drilling operation.

For vertical wells, hole cleaning is proper when the flow velocity is such that drag forces on the rock cuttings can support their apparent weight. Then the velocity of the cutting is the fluid flow velocity minus the settling velocity. And as settling velocities are considered small, velocity of the cuttings is taken as that of the mud. Therefore the time that it takes for the mud to travel from the bottom of the well to the surface (a "bottom-up" time) is considered as the time needed to carry the cuttings out of the well.

When flow circulation is stopped, for drill pipe change or other operations, the mud is designed to maintain the cuttings and limit sedimentation. The fluid exhibits a yield stress that can support the weight of the cuttings. Sedimentation mechanisms in shear-thinning fluid with yield stress are not yet well understood. For example, many settling velocity correlations exist for one particle in non-Newtonian fluids, but do not match very well with measurements. Moreover, only a few studies concern settling mechanisms of diluted or concentrated suspensions in non-Newtonian media.

For deviated and horizontal wells hole cleaning is much more difficult and knowledge on the subject is still deficient. Cuttings settle in the radial direction of the flow and a solid bed can form in the well. Mean velocity of the solid phase is much lower than the mud velocity and it needs several "bottom-up" times to clean the well. The bed of particles can be static and accumulation of solid can lead to blockage of the flow. Much experimental work has been done with large flow loops trying to determine correlations for the minimum flow allowing hole cleaning [1, 2]. A mechanical approach considering the equilibrium on one cutting at the bed interface also gives information on the minimum velocity to transport the cuttings [3]. However, the properties of the bed of particles are still difficult to characterize. The determination of the condition of flow, static bed or moving bed,is not easy. Further extended research is still needed tocharacterize in a better way the hole cleaning in deviated wells.

\subsubsection{Cuttings Re-Injection}

Another issue related to drilling muds and cuttings is the injection of the drilled particles in a specific well for disposal. Indeed, in specific areas like the North Sea for example, reject and disposal of the cuttings wet with the drilling mud in the sea is or will soon be forbidden.

A first solution is to transport all the cuttings on shore and to proceed to special treatment. But this solution can be very expensive and cleaning or chemical treatment on the platform can be complex due to the lack of space.

Re-injection in a particular well can then be an alternative solution. Cuttings are crushed and remixed with a polymer solution to create a dense paste. The mixture is then pumped into the specific well and a fracture is created and filled with the slurry. The control of viscosity is of great importance in this technique. The cuttings "slurry" must not exhibit a too large apparent viscosity or a large yield stress and settling of the solid phase must be avoided.

With the increase of environment constraints, the use of the re-injection should be a realistic solution in the future. Studies on pasty material and dense suspensions should be very valuable to characterize the cuttings slurry.

\subsection{Cements}

Like drilling mud, cement is an essential fluid in drilling operations. It is the material used to seal the annular spaces between the casing string and the borehole walls. The major goal of the cementing operation is to prevent any circulation of gas, oil or water between different rock layers and to mechanically fix the tubing in the well.

The cement powder is a mix of clay and limestone heated to high temperature and then crushed. A fine solid residue is obtained and additives like gypsum can be added.

Oilfield cement is thinner and exhibits far less strength than cement or concrete used for construction due to the requirement that it must be highly pumpable in relatively narrow annuli over long distances. Various additives are used to control density, setting time, strength and flow properties. The cement slurry, commonly formed by mixing the cement powder and water (Fig. 2) is pumped into place and allowed to solidify (typically for 12 to $24 \mathrm{~h}$ ) before additional drilling activity can resume. 
The amount of solid is large in typical cement. The volume fraction (around 50-60\%) is close to the packing fraction, but it the same time, it must keep fluid properties when being introduced into the annular space. Therefore, rheological behaviour has to be controlled in a very careful way.

The cement slurry is a pastelike material that evolves in time due to chemical reaction. The characteristics of the system are in between solid and liquid. Due to particles dispersed in the bulk at high volume fraction, it's close to granular media but at the same time it can flow like a viscous fluid. Gelation occurs creating a solid phase with mechanical strength. All these phenomena make cement a very interesting system and at the same time a very important one for a large range of industries: the oil and gas industry, but also building of houses, bridges, tunnels, etc.

The specific properties needed in the case of drilling applications give rise to a wide range of research and development to characterize setting time, type of additives, rheological properties, etc.

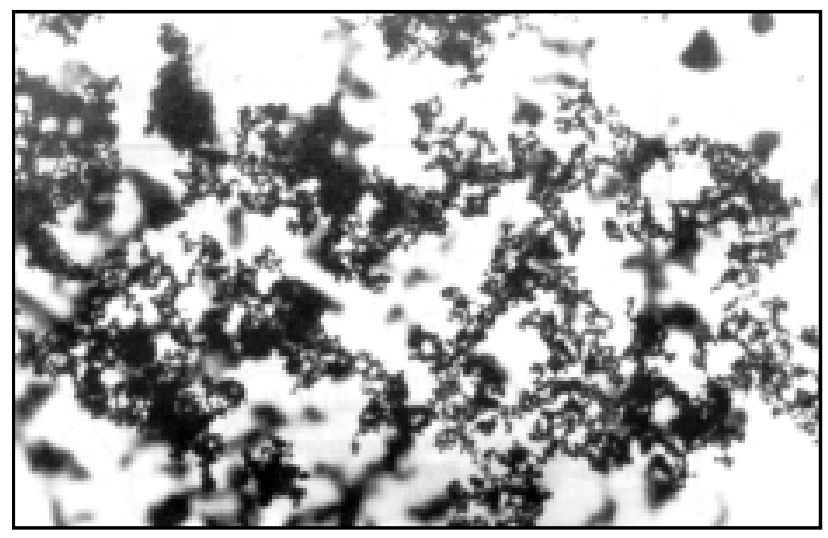

Figure 2

Cement suspension in water.

As we have seen previously with drilling muds, environmental issues are now a significant concern for a majority of people and therefore for oil companies through new legislation. Proper well abandonment is now a major problem with the increase of well closing. Long term durability and proper placement of the cement plug is asked for well abandonment. This has generated numerous efforts to characterize long term evolution and chemicophysical change of the cement structure under stress with time.

Despite its large use, this solid/liquid dispersion still prompts many questions. Cement that starts as a fluid and evolves to a very strong solid is a good example of the richness of such dispersed systems.

\subsection{Gas Hydrates}

Hydrates crystals are molecules composed of a solid cage of water stabilized with gas molecules. Different crystalline structures (I, II and H) are possible corresponding to the assembly of the atoms. The thermodynamic conditions of existence of these molecules are high pressure and low temperature as shown in Figure 3.

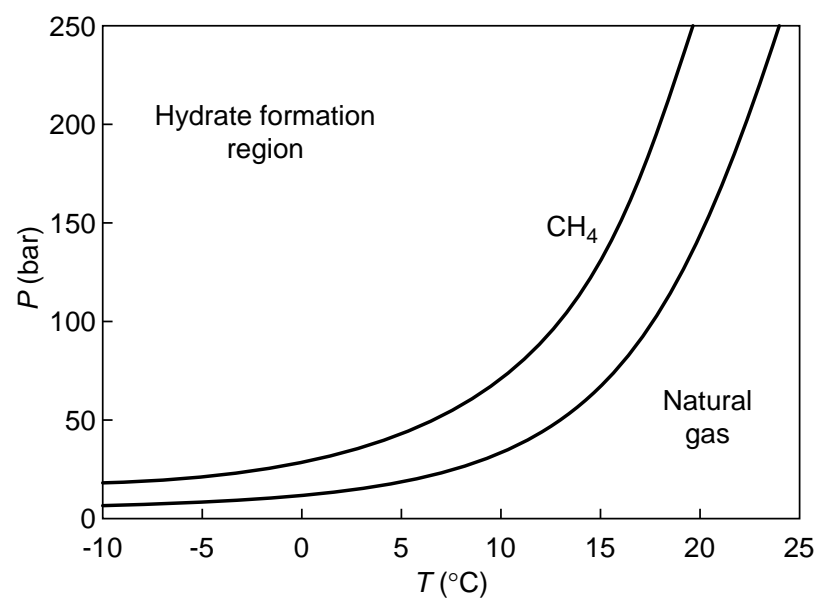

Figure 3

Hydrate dissociation curve.

In offshore zones, these conditions of temperature and pressure are common. So for production lines at the sea bottom, if water, oil and gas are present together, which is frequently the case, hydrates crystals are likely to form. Water is then turned into solid particles and this mechanism can lead up to the blockage of the flow lines.

One conventional approach to avoid hydrate formation is to inject thermodynamic inhibitors like methanol or glycol. The additives change the conditions of dissociation of hydrates. But this involves adding a lot of extra liquid to the well flow. Besides implying a logistics problem in supplying large amounts of liquids to an offshore site, the extra liquid increases the gravitational pressure drop due to the weight added by the inhibitor, which may reduce the production capacity of the line. The problem is aggravated by the large elevation differences involved in deep offshore fields. Further, with the low temperatures and high pressures often involved, the amount of thermodynamic inhibitor added may be excessive.

An innovative technique is possible which consist of using anti agglomerate inhibitors. These chemicals have the advantage of working at very low doses. Based on surfactant properties, they maintain a dispersion of small solid particles 
in the flow. The mixture is then transported through the pipe. The new properties of the solid dispersion in hydrocarbon phase are very important to assure that production can continue in the presence of these particles.

Contrary to drilling mud and cement, hydrate particles in production fluids do not always form a well mixed system. Solid phase can settle, agglomerate or remix depending on flow conditions. So sedimentation problems, hydrodynamic properties like slip velocities are some of the issues of hydrate transportability.

\subsection{Rock Particles}

Production of sand with the hydrocarbon fluid is a problem that can be serious for some fields. Indeed, the vicinity of the well bore is submitted to forces due to the flow of production fluids in the well. For weakly consolidated rock media, an erosion process can occur and grains are detached and produced within the fluids. Different solutions are proposed to remove sand particles. Rock grains can be blocked at the well bore with artificial granular media, a gravel pack, which trap the rock particles. A special grid can also be installed at the production zone.

The placement of the gravel pack can be a difficult problem in the case of deviated or horizontal wells. Indeed, the granular mixture is injected in the well through the pipe and fills the annular space between the walls of the hole and a specific grid that was placed previously.

The displacement of the gravel pack can present specific problems related to transport of dense suspension or viscous paste.

Today, oil companies are tending also towards "sand management" by trying to optimize sand production while maximizing well efficiency. In this case, sand is flowing with the fluid and separated at the surface and it is therefore not necessary to prepare the well with particular conditions (gravel pack or grid). The index of production is better but surface separation must be done. Achieving "sand management" requires a good knowledge of the amount of sand that will be produced by a well as a function of the production conditions. It is still difficult to model the volume of sand eroded for specific production conditions. The granular properties of the porous media have to be taken into account and interaction of the fluid and the rock particles from a physical and chemical point of view are important.

\section{PROPERTIES OF DISPERSED SYSTEMS}

In the previous Section, we presented different solid and liquid mixtures that are prepared, used or encountered in the different operations conducted in the drilling and production area. The liquids are very different from one another: water, light oil, heavy oil, emulsion of brine in oil, aqueous solutions of polymer and clays, etc. The properties, sizes, shapes of the particles can also be very different: rock cuttings, cement powder, hydrates crystals, sand particles, etc.

The size range is from $1 \mu \mathrm{m}$ for the cement powder to $1 \mathrm{~cm}$ or sometimes more for the largest cuttings transported by drilling mud. Density of the hydrate particles is close to 1 , and more than 4 for the barite used as a weighting agent for mud. Dense systems can be found where the volume fraction can be very close to the maximum packing fraction: up to $60 \%$ in the case of cement powder, or at packing when particles are forming compact beds (hole cleaning in horizontal wells).

The interstitial fluid has a large range of properties. From very low viscosity, less than $1 \mathrm{mPa} \cdot \mathrm{s}$ for the case of condensate oil with hydrates to very high viscosity (1 Pa.s) for crude oil in the case of cold production of heavy oil with sand for example. Non-Newtonian behaviour of the liquid phase can also be found, essentially shear-thinning effects.

Despite their large variability, we can find common properties between these different systems. In the drilling and production area, we are mainly concerned with the flow properties of such mixtures. Homogeneous or separated flow can occur depending on the flow parameters. So we can first try to classify these different systems in terms of separated or homogeneous regimes. Then, common features of these system in terms of physical stability, rheology and microstructural interactions will be discussed.

\subsection{Flow Patterns}

The first studies dedicated to solid and liquid transport in pipes tried to determine the main flow regimes encountered. A classification is naturally proposed depending on the total flow rate at the inlet of the system.

An example is given in Figure 4 established by Turian and Yuan in 1977 [4]. These authors tried to organise the flow regime starting from the simplest one: homogeneous flow at high velocities.

This classification was completed by others authors $[5,6]$ and four main flow regimes are commonly proposed. They are schematically represented in Figure 5.

At large flow velocities, the turbulent mixing is high enough to maintain a homogeneous dispersion of solid in the liquid phase. In laminar flows, diffusion processes of the particles under shear $[7,8]$ have been shown and this effect can limit the settling and produce resuspension phenomena. In both cases, the volume fraction of solid in the tube can be considered as constant in space and time (for time scales larger than the time scale of fluctuations in the case of turbulent mixing). When mean flow rate decreases, the mixing or resuspension mechanisms can be of the same order of magnitude as the gravity effect and nonhomogeneous suspensions are observed. The solid 

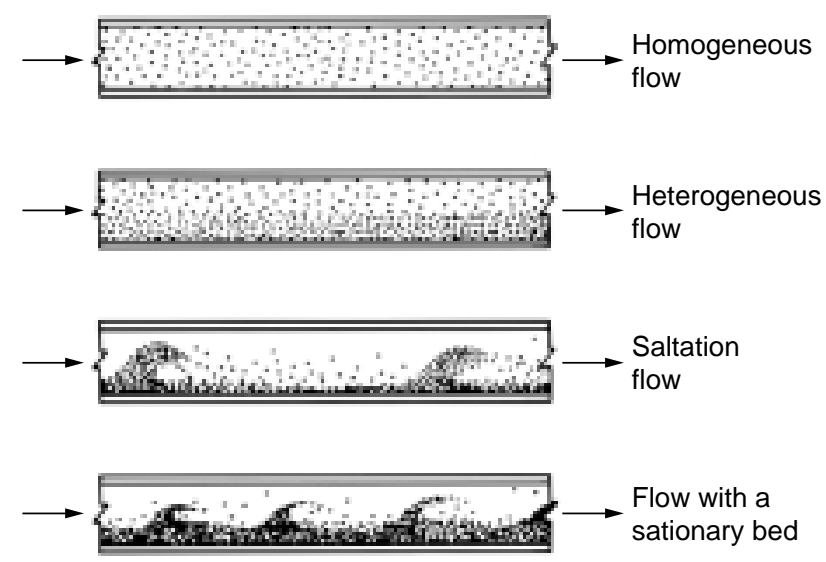

Figure 4

Turian and Yuan (1977): flow regime classification. From top to bottom: the mean flow rate is decreasing.

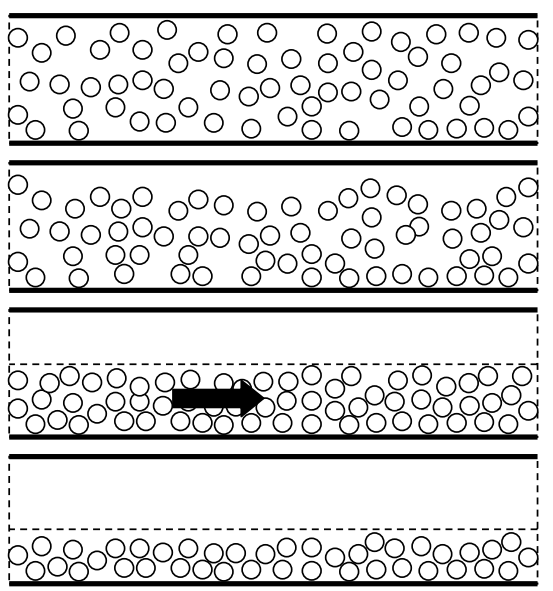

Homogeneous

suspension

Heterogeneous

suspension

Moving bed

Stationary flow

Figure 5

Main flow regimes for solid/liquid transport. From top to bottom: the mean flow rate is decreasing.

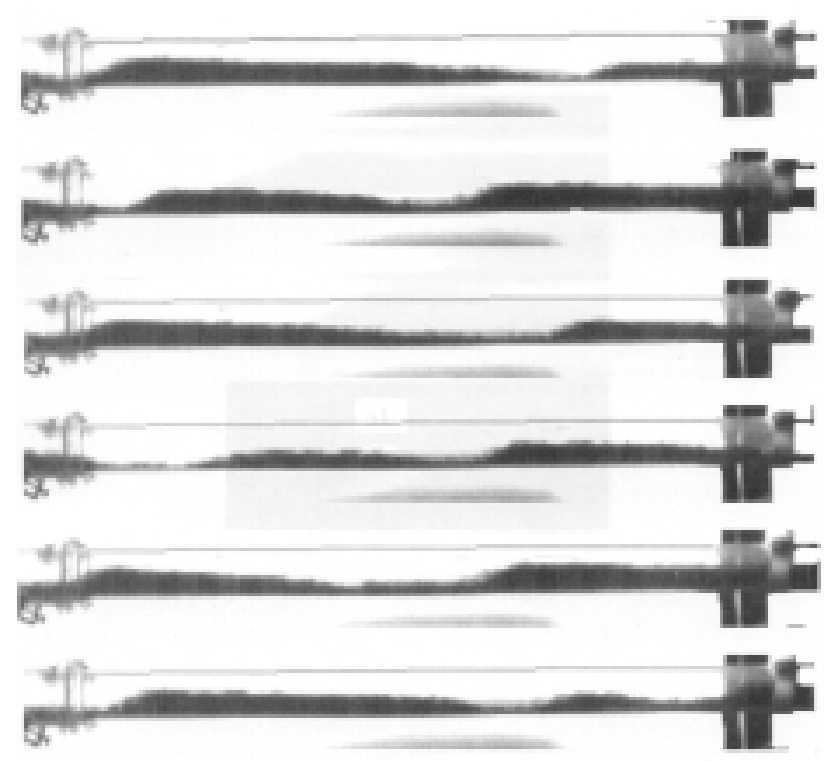

Figure 6

Dunes at the interface between bed and liquid (Simkhis, 1998).

distribution is non-symmetric in the radial direction of the pipe [9]. When velocity continues to decrease, the limit deposition velocity can be reached and a bed of solids is formed. Below this value, two flow regimes are then considered: moving bed or stationary bed where the solid phase does not flow.

Of course, frontiers between these main regimes are not simple and intermediary regimes can occur. When the bed of particles starts to flow, dunes and waves can appear at the interface [10, 11] (Fig. 6). A two layer bed can form with a stationary layer at the bottom and a moving bed on top of it. Homogeneous flow can also be more complex because of radial flow of particles and then complex radial distribution can be found $[12,13]$.

Specific theoretical frameworks can then be used to model homogeneous flow as a dilute suspension, colloidal dispersion, granular media, etc., and nonhomogeneous flow as two layer flow, slug flow, annular flow, etc.

Flow regime determination by flow maps was first based on a set of experimental data and dimensional analysis

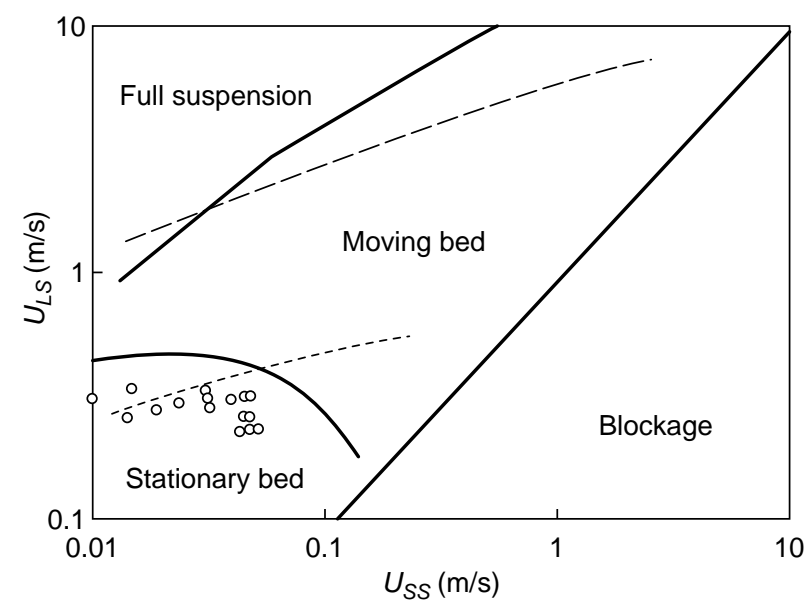

Figure 7

Flow map and data in the stationary bed regime (Doron and Barnea, 1996). 
(Turian et al. in the 1970's). Development of models, like the two layer model [14-16] give more predictive possibility for the classification. Figure 7 gives an example of a flow map with frontiers calculated with a three layers model.

Determination of the flow map is a simple tool to estimate roughly the distribution of solid in the liquid. It helps to classify solid/liquid system in terms of homogeneous or nonhomogeneous system.

\subsubsection{Drilling and Production Systems}

Starting from the typical flow velocities and the average particle sizes of the drilling and production systems presented in the previous section, we can try to classify them according to the two families: homogeneous dispersion or separated phases.

We have tried to find out what are the main regimes during flow in pipes. Of course, many possibilities can arise depending on flow geometry and field parameters, but when we look at the typical range of flow rate and the order of magnitude of the operating conditions for the different dispersed media, it is possible to have an overview of the typical flow regimes.

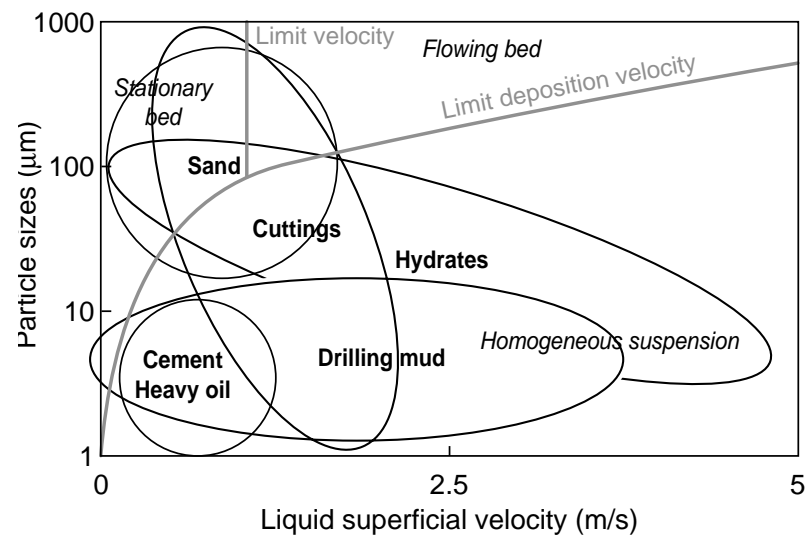

Figure 8

Main flow regimes for the different systems present in drilling and production.

The flow map of Newitt et al. [5] is the basis of the classification. Figure 8 represents schematically a flow map with the limit deposition velocity separating a zone of homogeneous flow and a zone of flow with a bed of particles. The frontier between static bed and moving bed is also illustrated. In the Newitt classification, two flow regimes are considered when velocity is larger than the limit deposition velocity for a fixed size. The first one is a heterogeneous regime where all particles are dispersed but where the solid distribution is not symmetric in the pipe and the second one is homogeneous flow. For simplification, we will consider only homogeneous flow which is the preponderant one in terms of velocity range above the limit deposition velocity. The order of magnitude of velocities and sizes are represented. This very schematic representation gives the typical type of flow regime encountered.

For cement, heavy oil and drilling mud, the flow pattern is mainly homogeneous. Separation of the phases is uncommon and occurs in only very specific conditions. In the second family, fluid and particles can separate or be remixed with the flow conditions like a two-phase separated system. Hydrates in hydrocarbon fluids, cuttings in drilling fluids, sand production in hydrocarbon are members of this second family.

Homogeneous dispersion will be well described by rheological characterization of the effective media and separated systems will be considered as two-phase systems. Remixing, settling effect, instability/stability of the configuration will be important for this family.

\subsubsection{Stability}

A solid dispersion in a liquid is considered stable if the mean distribution of the particles is stationary in time and space. But in most cases, the difference of density between solid and liquid tends to separate them in the gravity field. Stratification of the flow and creation of a sliding or stationary bed is the result of settling effects. This mechanism is responsible for the very poor cleaning in deviated and horizontal wells and is also the cause of bed formation of sand or hydrate particles in pipes.

Despite their simplicity, sedimentation processes are still not well understood. Settling velocities can be estimated in a Newtonian media for different types of particles [17] (spheres, ellipsoid, and cylinders) and in laminar regimes. But the determination of suspension velocities is much more complex because of the slow decrease of the velocity field around a sphere leading to long range hydrodynamic interactions [18]. These multibody interactions produce huge velocity fluctuations in settling suspensions [19]. Studies have tried to understand the origin of the large fluctuations in the system but many questions remain [20,21].

In shear-thinning, thixotropic or yield stress fluids, settling mechanisms have not been widely investigated. Most studies focus on sedimentation velocity of a single sphere in different fluids [22]. But suspension velocities are still not well understood.

Stability is often an important issue for dispersed systems. Indeed, for cement and drilling mud, the prepared mixture must stay well mixed over the time scale of use (typically the day). 


\subsection{Rheology}

A common feature of these systems is a complex rheological behaviour. Indeed, the different systems that we listed are composed of a fluid that itself can be a complex structure with different additives in interaction, but the solid phase can interact also in several ways such as hydrodynamic interactions, Brownian motion, collision, friction, etc.

Dispersions of solids in a liquid give rise to an increase of the apparent viscosity. This increase can be well described by a Krieger-Dougerty law [23] for dispersion in Newtonian fluids and for volume fractions less than $30-40 \%$. When the fraction of solid reaches the maximum packing, divergence of the viscosity is observed and then the prediction is very sensitive to the packing evaluation.

Non-Newtonian effects like shear-thinning can also be observed. Indeed, when interparticle forces can cause aggregation and formation of clusters, the competition between aggregation and shear break up leads to shear-thinning behaviour. Networks build up, between solid particles and polymer for example, giving rise to gelation process and yield stresses. Very often, the flow behaviour is then described to a first approximation by a Bingham model.

Drilling muds for example are usually describe as Bingham plastic fluids. For many years, viscosity was (and is still) controlled on the field with the Marsh funnel test. The viscosity was then defined using only one parameter: the Marsh viscosity. But now, with the generalisation of the Couette rheometer (Fann 35, Fig. 1) in the field, rheograms are obtained to characterize the constitutive law of the system. At first only two points (for two rotation speeds) were recorded and so a Bingham plastic model was used. Nowadays, six points are common and a more accurate description is gaining acceptance: the Herschel-Bulkley model.

In both cases, a yield stress is associated and its value is calculated from extrapolation of the rheogram at zero shear rate. For hydraulic calculations and pressure drop determination, the Herschel-Bulkley or Bingham model is a good enough representation of the fluid constitutive law in most cases. But for other flow situations, the determination of the value of the yield stress is of great importance. For settling behaviour for example, the yield stress will indicate the maximum size of cuttings that are supported at rest. For hole cleaning in horizontal wells, the position of the drill pipe is not central in the annular leading a narrow and a wide gap. In the narrow gap, the mud can be in static flow depending on the yield value. An error on this value can indicate a bad cleaning or a good one and the decisions in the drilling operation can then be very different.

Cement pastes are also considered as Bingham fluids. The determination of the yield value is of importance for the placement conditions. The yield stress value can give an indication of the conditions of mud removal in the annulus.
Yield stress characterization is a practical problem that is still difficult to handle. Indeed, extrapolation of the rheogram measurement to zero shear rate is not satisfactory. The definition of the yield stress from a more fundamental point of view is not easy. Recent studies [24, 25] showed that time effects and yield stress are linked closely and careful rheological characterization must be done to evaluate it.

In some circumstances, the solid nature of the particles can give rise to high friction forces between the grains. This "granular effect" can produce shear-thickening of the equivalent media or even blockage of the flow. This effect is observed in cement paste but also for drilling mud and hydrate systems. Indeed, when the hydrate fraction or the cutting fraction is too high, blockages of pipeline or drilling well are observed. The understanding and the forecasting of this behaviour are very important to avoid such problems.

The coupling of microstructural measurement with classical rheometer investigation is a powerful tool to understand the properties of the dispersed matter. The definition of the type of microstructure and the main forces acting on particles is relevant for the characterization of such systems.

\subsubsection{Microstructural Interactions}

Coussot (1999) [26] have tried to classified solid/liquid dispersion in different domains depending on the specific mode of interaction. Particles distributed in a fluid are classified depending on the shear rate of the flow and the volume fraction of solid. Sizes, nature of the particles and properties of the fluid are fixed. Figure 9 represents schematically this classification. Hard suspensions and soft suspensions are dissociated when the packing volume fraction $\phi_{c}$ is obtained.

For dense suspensions where a majority of the particles are in contact, three modes of interaction can be found: friction, collision and lubrication. Dimensionless numbers representing the ratio of one effect to the other allow frontiers between regimes to be estimated. A boundary is defined when the dimensionless number is equal to 1 . The Leighton number Le, for example, compares the effect of friction and lubrication (for more details, the reader can refer to [26]).

For soft suspensions, different interaction regimes can be defined: colloidal interactions, Brownian motion, hydrodynamic interactions and turbulence. Very different types of interaction can be found in these different mechanisms. Here again, dimensionless numbers can be defined to separate the different domains.

It is then possible to analyse the main mode of interaction for dispersed system. Each domain is characteristic of a certain type of model media and is related to theoretical framework that can be applied.

\section{Drilling and Production Systems}

If we look at the mode of interaction, we can observe that very different media like cement paste and slurries of hydrate can have very similar properties in some specific conditions. 


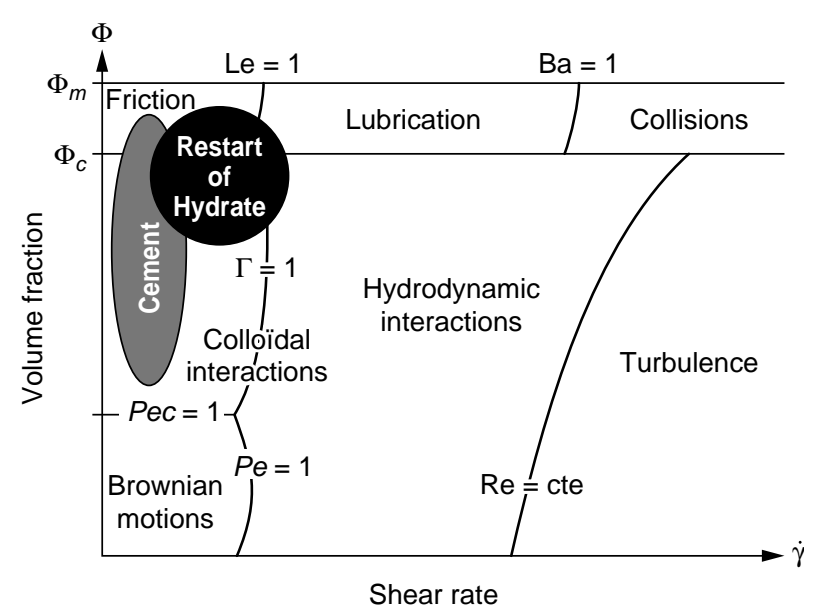

Figure 9

Schematic of Coussot classification. The mode of interactions between particles is represented versus solid volume fraction and shear rate of the flow. The frontiers are defined by dimensionless numbers (Le: Leighton number; Ba: Bagnold number; Re: Reynolds number; Pe: Peclet number; $\Gamma$ : ratio of colloidal interaction and hydrodynamic interactions). Example for cement and hydrates slurries is also represented.

In the case of hydrates formed in an offshore pipeline using low dosage antiagglomerate additives, limited sizes of solid particles are transported with the fluid phases but the system no longer evolves from a chemical point of view after the formation stage. For certain hydrocarbon phases, only weak interparticle forces remain (van der Waals). So when the flow stops, a packed bed of particles can form and it can be shown that friction between the grains will be the dominating mechanism in a restart situation (when interstitial fluid is of low viscosity).

Is has been stressed also that shear-thickening properties in cement pastes are related to the friction between the grains (see article Lootens et al. in this dossier). Strong chains of contact by friction form in the bulk and blockage can be observed in particular conditions.

The flow properties of these two systems are related to the "granular" characteristics and the properties of the solid friction between the grains is much more important than viscosity of the interstitial liquid (Fig. 9).

Analysis of the dominant interparticle interactions can link actual systems to model ones where a theoretical framework exists. Naturally, real systems are often more complex and combinations of model must be used to describe them.

\section{SOLID DISPERSIONS IN DRILLING AND PRODUCTION}

In this article, we have tried to draw an overview of the different liquid/solid systems that are found in the drilling and production area. We have presented each system and we have tried to show the similarities between them. A great deal of work has been done by IFP with partners from academia on dispersed system and to go deeper in such questions, the dossier continues with specific articles on these systems. Studies related to the three important dispersed media are presented: cement, hydrate and drilling mud.

The first article is related to the determination of the constitutive law of drilling mud. The experimental work presented in this first article allows the measurement in detail and with confidence of the constitutive law of a water-based mud and an oil-based mud. A rheometer coupled with a nuclear imaging system give powerful results to characterize the viscosity of the system. Discussion about yield stress, thixotropy and the link between the two give new insights into drilling mud rheology.

The second article is related to cement slurries. The rheological behaviour of the cement dispersion in water is investigated. Different elementary behaviours are observed: gel formation, shear-thinning, and shear-thickening. The role of chains of grains at contact is analyzed.

The third system presented is hydrates dispersion in hydrocarbon fluids. A specific remediation technique using chemical antiagglomerate additives has been developed at IFP and the characterization of the rheology and flow properties of such mixtures has generated a great deal of research and development. Here again, many different behaviours can be observed depending on the relative properties of the liquid phase.

The last two articles are not dedicated to a particular drilling and production system, but common properties of dispersed media are analyzed: the sedimentation process in non-Newtonian media and solid phase distribution under flow in pipe.

Sedimentation process in shear-thinning fluid is studied experimentally with a model system composed of monodisperse spherical particles in a shear-thinning solution of polymer. Nonhomogeneous settling is shown. The bulk of the suspension is a particular structure with dense columns and more dilute regions. The sedimentation process of such system presents different phases that are described.

Settling mechanisms can be found in almost every system we have mentioned. But in drilling fluids with cuttings or in hydrate flow in crude oil, shear-thinning behaviour are common.

Buoyant particles in tube flow can evolve to inhomogeneous radial distributions. Experiments on pipe flow of suspensions indicated that significant deviations from ideal Poiseuille flow can occur in the presence of particles. The article focuses on fluid-particle interactions that can induce lateral migration in a shear flow. Inertial migration is analysed but other types of radial movement are presented (polymeric and viscoelastic fluids, where the nonlinearity results from the non-Newtonian behaviour of the suspending fluid). 
The knowledge of the radial distribution of solid is very important in many cases to characterize transport properties of the solid phase.

\section{CONCLUSION}

Drilling and production techniques have significantly evolved to face the new challenges of complex well development. Dispersed media of solid particles in fluids are common in these operations: cement, drilling fluid, hydrates dispersion, rock and sand particles in production fluids, etc. Solid/liquid media have rich and various behaviours, at the limit between liquid and solid and we try, in this dossier, to show the variety of these properties and characteristics.

A first family of "homogeneous" mixtures can be formed composed of cement paste and drilling fluid. For these systems, an equivalent fluid can be defined and the problem is the definition of the rheological properties of this medium. Increase of apparent viscosity is a common feature of the dispersed system, but non-Newtonian properties are also observed. Shear-thinning or shear-thickening, time evolution, yield stresses are typical in these complex fluids.

Another family is composed of solid/liquid system in separate phases. Different flow regimes and variable solid distributions are characteristic of this family. Settling, remixing, instabilities, interfaces problems are key issues. Drilled cuttings transported by the mud, hydrates particles in pipelines, sand production in oil are examples of this family. A multiphase model framework is adapted to evaluate the transport properties of these mixtures.

The complexity of these systems comes from the fact than the two phases can interact in many ways. The variety of interparticle interactions is large and combinations can also exist. The mixture can be alternatively one of the following "model" systems: dilute dispersion, concentrated suspension, paste material, granular media, colloidal suspension, etc. Of course, in some conditions, the homogeneous approximation can be sufficient to characterize the properties, but often the dispersed media can evolve from separate phases to homogeneous distribution and vice versa.

Dispersed systems are fascinating because of their rich behaviour and the many surprising properties that one can encounter. And if a lot of different systems are present in the drilling and production area, many other different products are also elaborated in very different industries: paint materials, food paste, cosmetic products, etc.

\section{REFERENCES}

1 Luo, Y., Bern, P.A. and Chambers, B.D. (1992) Flow-Rate Predictions for Cleaning Deviated Wells. IADC/SPE 23884.

2 Luo, Y., Bern, P.A., Chambers, B.D. and Kellingray, D.S. (1994) Simple Charts to Determine Hole Cleaning Requirements in Deviated Wells. IADC/SPE 27486.
3 Clark, R.K. and Bickham, K.L. (1994) A Mechanistic Model for Cuttings Transport. SPE 28306.

4 Turian, R.M. and Yuan, T.F. (1977) Flow of Slurries in Pipelines. AIChE Journal, 23, 232.

5 Newitt, D.M., Richardson, J.F., Abbott, M. and Turtle, R.B. (1955) Hydraulic Conveying of Solids in Horizontal Pipes, Trans. Instn. Chem. Engng., 33, 93.

6 Durand, R. (1953) Basic Relationships of the Transportation of Solids in Pipes-Experimental Research. Proc. 5th Minneapolis Int. Hydraulics Convent, 89.

7 Leighton, D. and Acrivos, A. (1986) Viscous Resuspension. Chemical Engineering Science, 41, 6, 1377.

8 Leighton, D. and Acrivos, A. (1987) The Shear-Induced Migration of Particles in Concentrated Suspensions. J. Fluid Mech., 181, 415.

9 Morris, J.F. and Brady, J.F. (1999) Pressure-Driven Flow of a Suspension: Buoyancy Effects. Int. J. Multiphase Flow, 24, 1, 105 .

10 Simkhis, M., Creutz, M., Barnea, B., Taitel, Y. and Mewes, D. (1998) Hydrodynamic Characteristics of Wave Like Flow in Solid-Liquid Mixtures in Pipes. Proceeding of ICMF 98, Lyon.

11 Takahashi, H., Masuyama, T. and Noda, K. (1989) Unstable Flow of a Solid-Liquid Mixture in a Horizontal Pipe. Int. J. Multiphase Flow, 15, 5, 831.

12 Segré, G. and Silberberg, A. (1962) Behaviour of Macroscopic Rigid Spheres in Poiseuille Flow. Part 1: Determination of Local Concentration by Statistical Analysis of Particle Passages Through Crossed Light Beams. J. Fluid Mech., 14, 115.

13 Segré, G. and Silberberg, A. (1962) Behaviour of Macroscopic Rigid Spheres in Poiseuille Flow. Part 2: Experimental Results and Interpretation. J. Fluid Mech., 14, 136.

14 Wilson, K.C. (1976) A Unified Physically-Based Analysis of Solid-Liquid Pipeline Flow. Proc. 4th Int. Conf. on Hydraulic Transport of solids, Paper A1.

15 Doron P., Granica, D. and Barnea, D. (1987) Slurry Flow in Horizontal Pipes-Experimental and Modeling. Int. J. Multiphase Flow, 13, 4, 535.

16 Shook, C.A. and Roco, M.C. (1991) Slurry Flow - Principles and Practice. Butterworth-Heinemann Series in Chemical Engineering.

17 Happel, J. and Brenner, H. (1983) Low Reynolds Number Hydrodynamic, Martinus Nijhoff Publishers.

18 Batchelor, G.K. (1971) Sedimentation in a Dilute Dispersion of Spheres. J. Fluid Mech, 245.

19 Nicolai, H., Herzhaft, B., Hinch, E.J., Oger, L. and Guazzelli, E. (1995) Particle Velocity Fluctuations and Hydrodynamic Self-Diffusion of Sedimenting Non-Brownian Spheres. Phys. Fluids, 7, 12.

20 Segrè, P.N., Helbolzheimer, E. and Chaikin, P.M. (1997) Long-Range Correlations in Sedimentation. Phys. Rev. Lett., 79, 2574.

21 Tee, S.Y., Mucha, P.J., Cipelletti, L., Manley, S., Brenner M.P., Segre, P.N. and Weitz, D.A. (2002) Nonuniversal Velocity Fluctuations of Sedimenting Particles. Physical Review Letter, 89, 5.

22 Chhabra, R.P. (1993) Bubbles, Drops and Particles in NonNewtonian Fluids, CRC Press, Boca Raton. 
23 Krieger, I.M. and Dougherty, T.J. (1959) A Mechanism for Non-Newtonian Flow in Suspensions of Rigid Spheres. Transactions of the Society of Rheology, 3, 137.

24 Coussot, P., Nguyen, Q.D., Huynh, H.T. and Bonn, D. (2002) Avalanche Behavior in Yield Stress Fluids. Physical Review Letter.
25 Coussot, P., Nguyen, Q.D., Huynh, H.T. and Bonn, D. (2002) Viscosity Bifurcation in Thixotropic, Yielding Fluids. Journal of Rheology, 46, 3.

26 Coussot, P. and Ancey, C. (1999) Rhéophysique des pâtes et des suspensions, EDP Science.

Final manuscript received in January 2004 